\title{
Comparing optical properties of different species of diatoms
}

\author{
Maibohm, Christian; Friis, Søren Michael Mørk; Su, Y.; Rottwitt, Karsten
}

Published in:

Proceedings of SPIE

Link to article, DOI:

$10.1117 / 12.2078822$

Publication date:

2015

Document Version

Publisher's PDF, also known as Version of record

Link back to DTU Orbit

Citation (APA):

Maibohm, C., Friis, S. M. M., Su, Y., \& Rottwitt, K. (2015). Comparing optical properties of different species of diatoms. In Proceedings of SPIE: Organic Photonic Materials and Devices XVII (Vol. 9360). [93600B] SPIE International Society for Optical Engineering. Proceedings of SPIE - The International Society for Optical Engineering https://doi.org/10.1117/12.2078822

\section{General rights}

Copyright and moral rights for the publications made accessible in the public portal are retained by the authors and/or other copyright owners and it is a condition of accessing publications that users recognise and abide by the legal requirements associated with these rights.

- Users may download and print one copy of any publication from the public portal for the purpose of private study or research.

- You may not further distribute the material or use it for any profit-making activity or commercial gain

- You may freely distribute the URL identifying the publication in the public portal 


\title{
COMPARING OPTICAL PROPERTIES OF DIFFERENT SPECIES OF DIATOMS
}

\author{
C. Maibohm*a, S. M. M. Friis ${ }^{\mathrm{a}}$, Y. Su ${ }^{\mathrm{b}}$, K. Rottwitt ${ }^{\mathrm{a}}$ \\ ${ }^{a}$ Department of Photonics, Technical University of Denmark, Building 343 Ørsteds Plads, 2700-Kgs. \\ Lyngby, Denmark; \\ ${ }^{b}$ PLEN, Department of Plant and Environmental Sciences, University of Copenhagen, \\ Thorvaldsensvej 40, 1871 Frederiksberg C, Denmark;
}

\begin{abstract}
Diatoms are single cellular algae encapsulated in an external wall of micro-structured porous silica called the frustule. Diatoms are present in all water environments and contribute with $20-25 \%$ of the global primary production of oxygen by photosynthesis. The appearance of the frustule is very species dependent with huge variety in size, shape, and microstructure. We have experimentally investigated optical properties of frustules of several species of diatoms to further understand light harvesting properties together with common traits, effects and differences between the different frustules. We have observed, when incident light interacts with the micro-structured frustule it is multiple diffracted giving rise to wavelength dependent multiple focal points and other optical effects. Experimental results have been simulated and well confirmed by free space FFT propagation routine analysis software. The software uses parameters which are extracted from experimental images as basis for simulation and allows us to extract the influence of the different elements of the frustule. The information could be used both for predicting optical properties of diatoms and by changing frustule parameters, maybe by altering growth conditions of the diatoms tailor their optical properties.
\end{abstract}

Keywords: Diatoms, multiple interference points, nanostructured silica, FFT propagation routine

\section{INTRODUCTION}

Diatoms are a class of unicellular photosynthetic microorganisms and are among the most common phytoplankton in the oceans and other water environments. They have a colossal impact on the primary production of the world contributing with around $25 \%$ of the total amount equaling that of the rainforests [1,2]. Setting diatoms apart from other phytoplankton is the nanostructured silica shell surrounding the protoplasm, called the frustule unique for each of the over 200000 different species [2,3]. Even though well investigated the functionality of the frustule is not fully understood but it has been shown that the frustule provides the diatom with several properties; protection from mechanical and biotic stress, efficient nutrition uptake and light harvesting properties [4, 5-10]. In this work the focus how linear polarized monochromatic light is transmitted through the valve in air. In general when light interacts with the valve it causes either reflection giving rise to iridescence and part of the light can be coupled to the frustule and subsequently waveguided [7]. Or light can be transmitted through the valve where diffraction from the areolae or holes in the valve is the important effect. We have been interested in developing a simple description of the multiple "focus" points described in simulations at a distance corresponding to inside the frustule when light interaction with the valve of the centric species like Coscinodiscus wailesii $[8,10-15]$. Our experiments have been carried out in air which enhances the refractive index difference and thereby the diffraction effect compared to diatoms natural habitat; saline water. Our experimental findings are compared to simulations which allow us to identify important structural parameters necessary for application of the valves in devices or optical components.

Organic Photonic Materials and Devices XVII, edited by Christopher E. Tabor, François Kajzar,

Toshikuni Kaino, Yasuhiro Koike, Proc. of SPIE Vol. 9360, 93600B · ( 2015 SPIE

CCC code: $0277-786 \mathrm{X} / 15 / \$ 18 \cdot$ doi: $10.1117 / 12.2078822$ 


\section{METHODS AND MATERIALS}

\subsection{Morphology and sample preparation}

We have been investigating three centric diatom species which differ in frustule diameter, areolae density and areolae diameter. The selected species were harvested, cleaned to remove all organic material from the frustules and subsequently suspended in DI water. Morphological data was extracted from SEM and TEM images where a typical SEM image of the Coscinodiscus wailesii valve is seen on the left in figure 1 and all retrieved data is listed in table 1.

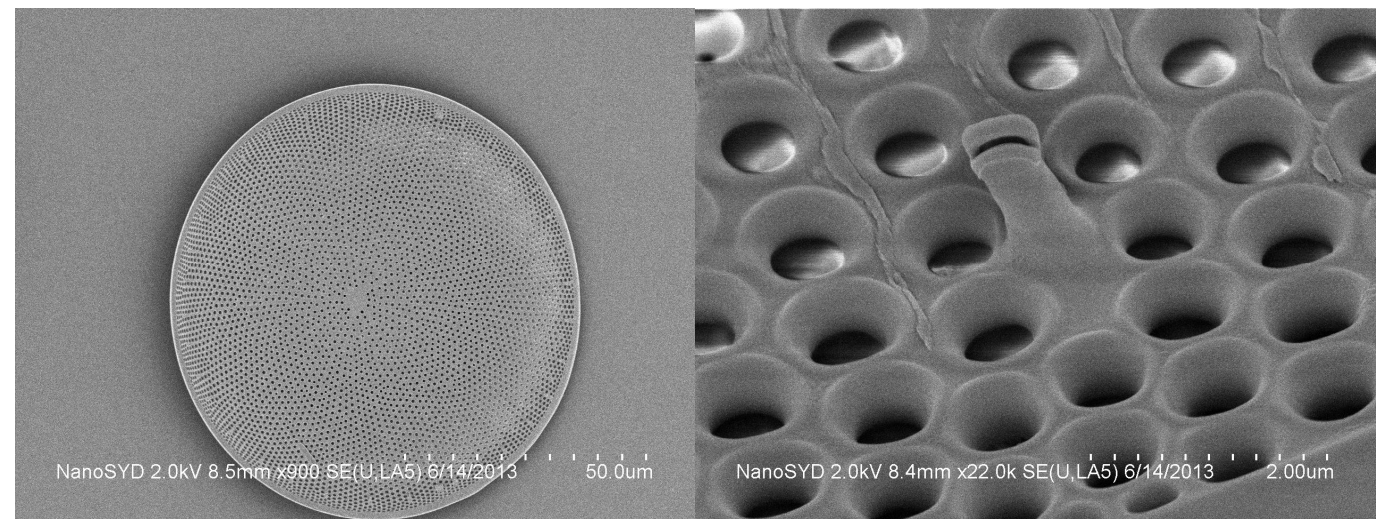

Figure 1: SEM images of the valve of Coscinodiscus wailesii. Left: The full valve is seen. Right: Zoom of the edge of the valve where the hexagonal pattern of the areolae is clearly observed and in the center of the image a rimoportula is seen protruding from the valve.

Table 1: Morphological data for the three investigated centric diatom species.

\begin{tabular}{|l|l|l|l|l|}
\hline Diatom name & Strain id. & $\begin{array}{l}\text { Frustule } \\
\text { diameter } \\
(\mu \mathrm{m})\end{array}$ & $\begin{array}{l}\text { Areolae number } \\
\text { within } 10 \mu \mathrm{m}\end{array}$ & $\begin{array}{l}\text { Areolae } \\
\text { diameter }(\mu \mathrm{m})\end{array}$ \\
\hline $\begin{array}{l}\text { Coscinodiscus } \\
\text { granii }\end{array}$ & Own strain; & $264.34 \pm 44.51$ & $6.5 \pm 0.80$ & $0.88 \pm 0.10$ \\
\hline $\begin{array}{l}\text { Coscinodiscus } \\
\text { concinnus }\end{array}$ & CCMP3377 from ncma.bigelow.org & $59.53 \pm 2.18$ & $11.2 \pm 0.48$ & $0.47 \pm 0.03$ \\
\hline $\begin{array}{l}\text { Coscinodiscus } \\
\text { wailesii }\end{array}$ & K-1048 from sccap.dk & $85.60 \pm 10.5$ & $7.43 \pm 0.5$ & $0.548 \pm 0.03$ \\
\hline
\end{tabular}

The valves of all three diatom species have a similar petri dish shape and with its areolae arranged in a hexagonal pattern as seen on the right in figure 1. Before the optical transmission measurements the diatom solution was drop-casted on a cleaned microscope slide and subsequently air-dried in ambient conditions.

\subsection{Experimental setup and numerical simulations}

For the optical transmission experiments the prepared samples were mounted on an x-y-z-stage with sub-micrometer precision and illuminated by linear polarized $632 \mathrm{~nm}$ HeNe-laser with a Gaussian beam profile. With the x-y-z-stage we could select, accurate position in the $x-y$-plane and move the valve on optical z-axis. To match the illumination area to the valve size of the two smaller species, and thereby reduce edge effects a pinhole was mounted in front of the valve. The laser beam was steered by guiding mirrors and the transmitted light through the diatomic valve was collected by an 
infinity corrected microscope objective (40X Nikon Plan Fluorite Imaging Objective, 0.75 NA, 0.66 mm WD). An image plane was created by a tube lens (Thorlabs ITL200 Infinity-Corrected Tube Lens for Plan Fluorite Objectives) and detection at the image plane was done with a high resolution color CCD camera (Thorlabs DCU224C $1280 \times 1024$ ). Each color channel (RGB) of the CCD camera was readout and analyzed independently while size determination is done by imaging a standard target (USAF and Standard Targets, Target Dot Diameter METRIC, Max Levy Autograph). A schematic representation of the experimental setup is seen in figure 2 .

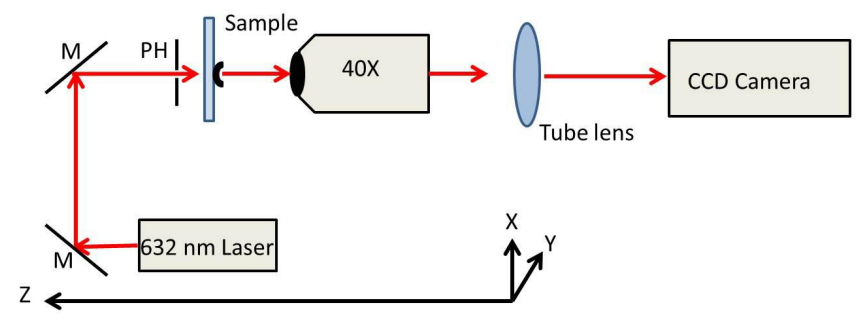

Figure 2: Experimental setup for transmission experiment. The sample is illuminated by a $632 \mathrm{~nm}$ laser source. In the figure the following are: (M) guiding mirrors, (PH) exchangeable pin hole, 40x infinity corrected objective with a NA: 0.75 and a tube lens to create an image plan at the position of the CCD camera

Light propagation through the valve is simulated by using a fast Fourier transform (FFT) approach where the output field is calculated at a distance $\mathrm{z}$ from the valve as described in [16]. The FFT algorithm is evaluated using Matlab and we have designed three different valve masks by using data from SEM and TEM images seen in table 1 . The most basic model of the valve is used where the following approximations are done; the areolae are fully transparent and the silica is totally opaque, the areolae is kept in a constant hexagonal pattern across the entire valve and the valve is flat with no curvature.

\section{RESULTS AND DISCUSSION}

In the optical experiments the valve is moved from the focus plane and in $1 \mu \mathrm{m}$ steps along the optical axis. At each step a high resolution CCD image is recorded thereby creating an image stack of cross-sections each corresponding to the intensity profile at that exact distance from the valve. These images are compared to evaluated cross-section profiles at equal positions from simulations. For all three species of diatoms we observe a series of constructive and destructive interference along the optical axis. The position of these bright and dark spots are species dependent i.e. dependent on the difference in morphology parameters between the species. If we regard Coscinodiscus wailesii as our standard which we measure against, the series of bright and dark spot on the optical axis starts at approximately $110 \mu \mathrm{m}$ for this species. In figure 3 typical cross sections from both simulations and experiments are shown. There is very good agreement of positions of both bright and dark spots between simulation and experiments. For Coscinodiscus concinnus the valve diameter, areolae size and areolae pitch is smaller compared to Coscinodiscus wailesii. We observe that the series of bright and dark spots starts closer to the valve at approximately $80 \mu \mathrm{m}$. In figure 4 we have shown typical cross sections from both simulations and experiments again with good agreement between simulation and experimental position of the bright and dark spots. We also observe a smaller or tighter bright spot for this species compared to Coscinodiscus wailesii. The last investigated species, Coscinodiscus granii has a larger valve diameter, areola size and areola pitch compared to both Coscinodiscus wailesii and Coscinodiscus concinnus. We observe in both simulations and experiments that the series of bright and dark spots for this species begins very far from the valve at approximately $1480 \mu \mathrm{m}$. In figure 5 both simulations and experimental cross sections with good agreement are shown. We observe for Coscinodiscus granii that the bright spot is less tightly confined compared to the two other species. 

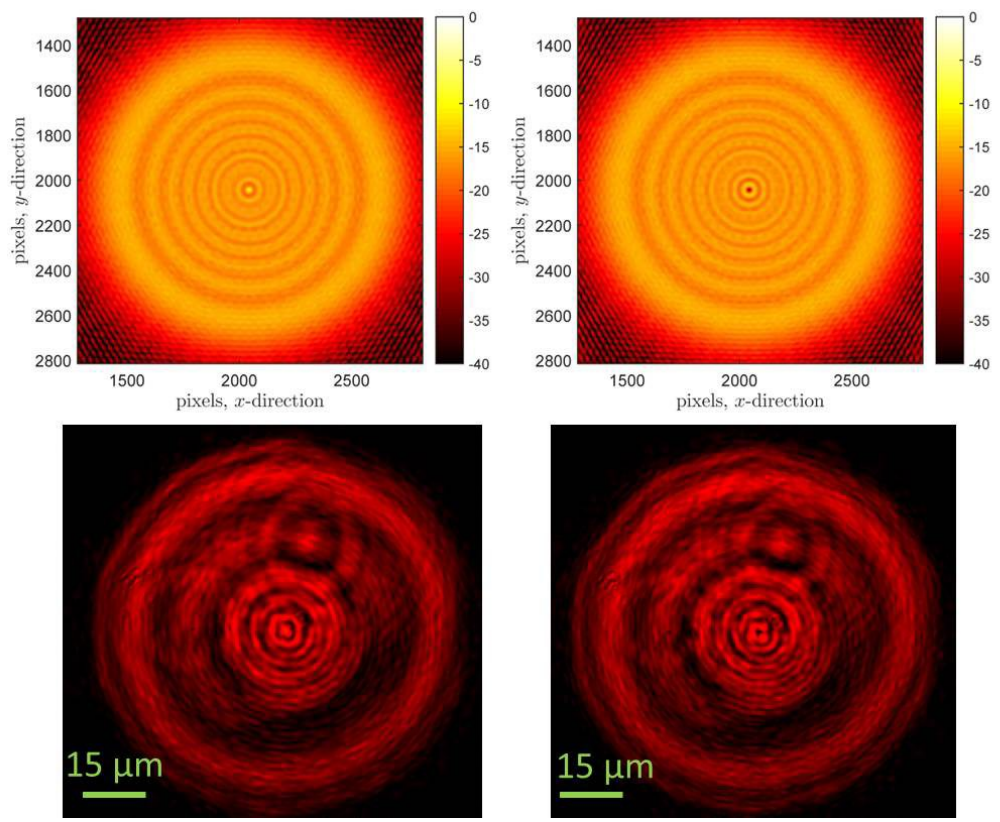

Figure 3: Top: Simulation of cross sections of Coscinodiscus wailesii where the color bars in $\mathrm{dB}$ and are relative to the input intensity before the valve. Left: constructive interference at $z=184 \mu \mathrm{m}$. Right: Destructive interference at $\mathrm{z}=175 \mu \mathrm{m}$. Bottom: CCD images of Coscinodiscus wailesii. Left: constructive interference at $\mathrm{z}=188 \mu \mathrm{m}$. Right: Destructive interference at $\mathrm{z}=176 \mu \mathrm{m}$
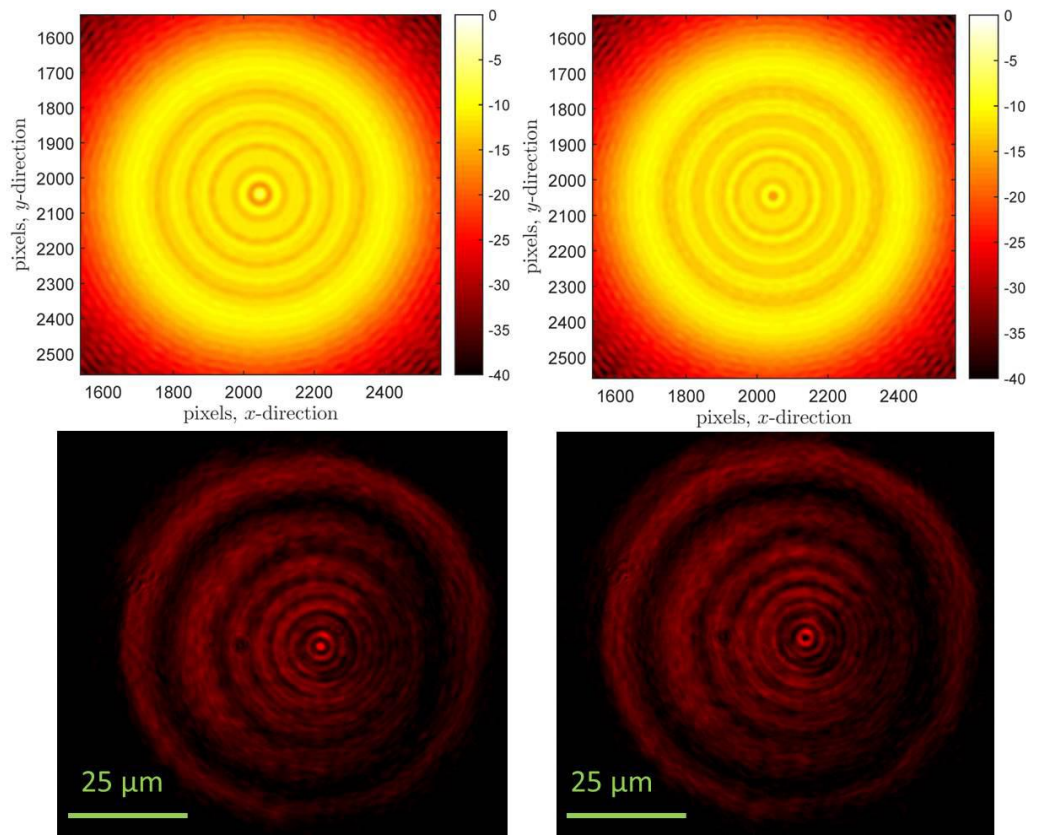

Figure 4: Top: Simulation of cross sections of Coscinodiscus concinnus where the color bars in $\mathrm{dB}$ and are relative to the input intensity before the valve. Left: constructive interference at $\mathrm{z}=168 \mu \mathrm{m}$. Right: Destructive interference at $\mathrm{z}=156 \mu \mathrm{m}$. Bottom: $\mathrm{CCD}$ images of Coscinodiscus concinnus. Left: constructive interference at $\mathrm{z}=168 \mu \mathrm{m}$. Right: Destructive interference at $\mathrm{z}=156 \mu \mathrm{m}$ 

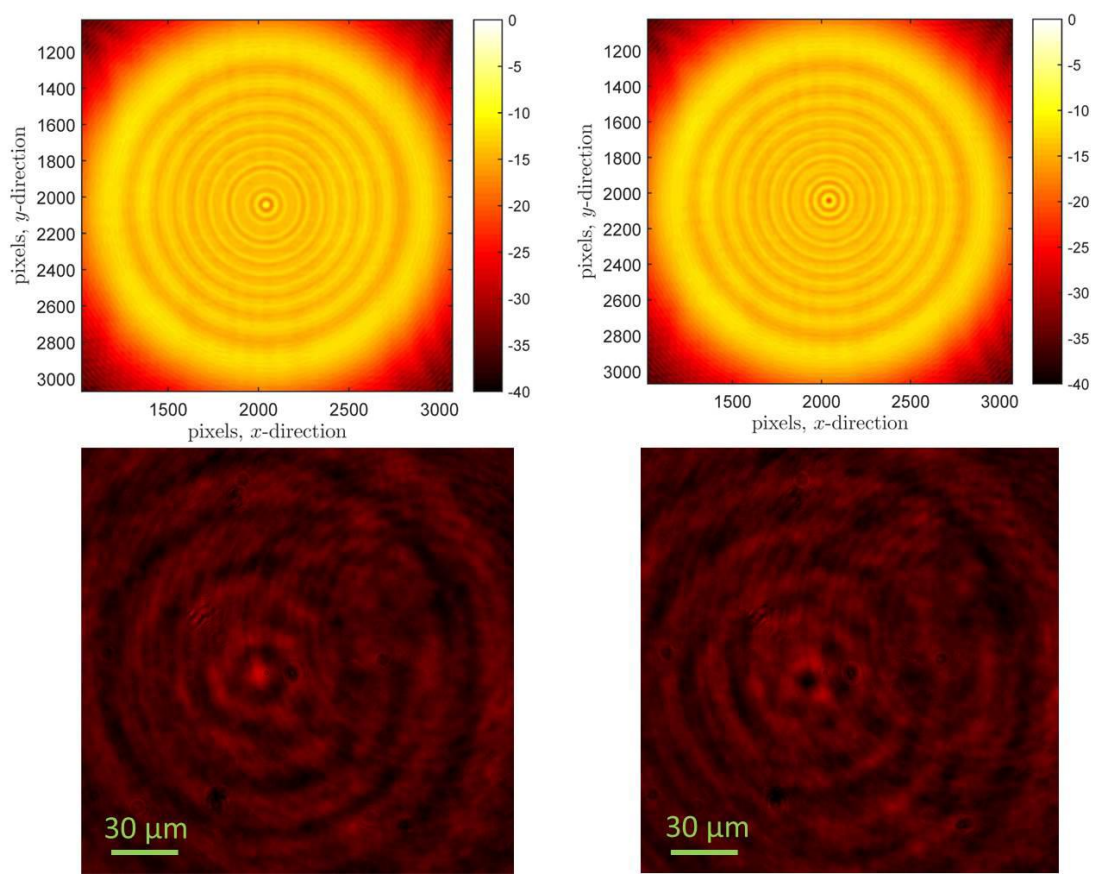

Figure 5: Top: Simulation of cross sections of Coscinodiscus granii where the color bars in $\mathrm{dB}$ and are relative to the input intensity before the valve. Left: constructive interference at $\mathrm{z}=1560 \mu \mathrm{m}$. Right: Destructive interference at $\mathrm{z}=1490 \mu \mathrm{m}$. Bottom: cropped CCD image of Coscinodiscus granii. Left: constructive interference at $\mathrm{z}=1572 \mu \mathrm{m}$. Right: Destructive interference at $\mathrm{z}=1480 \mu \mathrm{m}$

\section{CONCLUSION}

Light manipulation by all three centric diatoms show a series of constructive and destructive interference points along the optical axis. The difference in position of these points stems from morphological parameters such as valve diameter, areolae size and the pitch between areolae. Furthermore it has been shown that the spatial confinement of the bright spot also dependents on morphological parameters. Our FFT algorithm when evaluated with a basic mask that includes valve diameter, areolae size and areolae pitch can to a very high degree predict experimental findings for centric diatoms with hexagonal areolae pattern. These findings may lead to prediction of optical transmission properties of diatomic valves and applications in novel micro-optical components.

\section{ACKNOWLEDGMENTS}

This work was part of the project ALPHA, project number 12-127569 of the Danish Council for Independent Research | Technology and Production Sciences. 


\section{REFERENCES}

[1] Otto Pulz, Wolfgang Gross, Valuable products from biotechnology of microalgae, Appl Microbiol Biotechnol, 65: 635-648, (2004)

[2] Richard Gordon, Dusan Losic, Mary Ann Tiffany, Stephen S. Nagy and Frithjof A.S. Sterrenburg, The Glass Menagerie: diatoms for novel applications in nanotechnology, Trends in Biotechnology Vol.27 No.2, (2009)

[3] W. H. C. F. Kooistra et al. Evolution of Primary Producers in the sea (eds P.G. Falkowski \& A.H. Knoll, Elsevier, 207 (2007)

[4] James G. Mitchell, Laurent Seuront, Mark J. Doubell, Dusan Losic, Nicolas H. Voelcker, Justin Seymour, Ratnesh Lal, The Role of Diatom Nanostructures in Biasing Diffusion to Improve Uptake in a Patchy Nutrient Environment, , PLOS ONE, Volume 8, Issue 5, (2013)

[5] Christian E. Hamm, Rudolf Merkel, Olaf Springer, Piotr Jurkojc, Christian Maier, Kathrin Prechtel, Victor Smetacek, Architecture and material properties of diatom shells provide effective mechanical protection, Nature 421, 841-843, 20 February (2003)

[6] Dusan. Losic, Ken Short, James G. Mitchell, Ratnesh Lal, and Nicolas H. Voelcker, AFM Nanoindentations of Diatom Biosilica Surfaces, Langmuir, 23, 5014-502, (2007)

[7] T. Fuhrmann, S. Landwehr, M. El Rharbi-Kucki, M. Sumper, Diatoms as living photonic crystals, Appl. Phys. B 78, 257-260 (2004)

[8] Kieu K, Li C, Fang Y, Cohoon G, Herrera OD, Hildebrand M, Sandhage KH, Norwood RA, Structure-based optical filtering by the silica microshell of the centric marine diatom Coscinodiscus wailesii, Opt Express. 22(13):15992-9, (2014)

[9] Shigeru Yamanaka, Rei Yano, Hisanao Usami, Nobuaki Hayashida, Masakatsu Ohguchi, Hiroyuki Takeda, and Katsumi Yoshino, Optical properties of diatom silica frustule with special reference to blue light, Journal of Applied Physics 103 , 074701 (2008)

[10] Giuseppe Di Caprio, Giuseppe Coppola, Luca De Stefano, Mario De Stefano, Alessandra Antonucci, Roberta Congestri, Edoardo De Tommasi, Shedding light on diatom photonics by means of digital holography, Journal of Biophotonics, 7 (5): $341-50,2014$

[11] Luca De Stefano, Ilaria Rea, Ivo Rendina, Mario De Stefano, and Luigi Moretti, Lensless light focusing with the centric marine diatom Coscinodiscus walesii, Vol. 15, No. 26 / OPTICS EXPRESS, (2007)

[12] Shih-Hsin Hsu, Camille Paoletti, Moacir Torres, Raymond J. Ritchie, Anthony W. D. Larkum, and Christian Grillet, Light transmission of the marine diatom Coscinodiscus wailesii, Proc. of SPIE Vol. 8339 83390F-1, (2012)

[13] E. De Tommasi, I. Rea, V. Mocella, L. Moretti, M. De Stefano, I. Rendina and L. De Stefano, Multi-wavelength study of light transmitted through a single marine centric diatom, Vol. 18, No. 12 / OPTICS EXPRESS, (2010)

[14] Maria Antonietta Ferrara, Principia Dardano, Luca De Stefano, Ilaria Rea, Giuseppe Coppola, Ivo Rendina, Roberta Congestri, Alessandra Antonucci, Mario De Stefano, Edoardo De Tommasi, Optical Properties of Diatom Nanostructured Biosilica in Arachnoidiscus sp: Micro-Optics from Mother Nature, PLOS ONE, Volume 9, Issue 7, (2014)

[15] E. De Tommasi, I. Rea, L. De Stefano, P. Dardano, G. Di Caprio, M. A. Ferrara, and G. Coppola, Optics with diatoms: towards efficient, bioinspired photonic devices at the micro-scale, Proc. of SPIE Vol. 8792 87920O-1 (2013).

[16] N. Delen and B. Hooker, Free-space beam propagation between arbitrarily oriented planes based on full diffraction theory: a fast Fourier transform approach, JOSA A, Vol. 15, Issue 4, pp. 857-867 (1998) 